\title{
Article
}

\section{JAK3 Is Expressed in the Nucleus of Malignant T Cells in Cutaneous T Cell Lymphoma (CTCL)}

\author{
Chella Krishna Vadivel ${ }^{1}{ }^{\circledR}$, Maria Gluud ${ }^{1}$, Sara Torres-Rusillo ${ }^{1}\left({ }^{\circ}\right.$, Lasse Boding ${ }^{1,2}$, Andreas Willerslev-Olsen ${ }^{1}$, \\ Terkild B. Buus ${ }^{1} \mathbb{D}$, Tea Kirkegaard Nielsen ${ }^{1}$, Jenny L. Persson ${ }^{3,4} \mathbb{D}$, Charlotte M. Bonefeld $^{1}$, Carsten Geisler ${ }^{1} \mathbb{D}$, \\ Thorbjorn Krejsgaard ${ }^{1}$, Anja T. Fuglsang ${ }^{5} \mathbb{C}^{-}$, Niels Odum ${ }^{1, *}{ }^{-}$and Anders Woetmann ${ }^{1, *} \mathbb{C}$
}

1 LEO Foundation Skin Immunology Research Center, Department of Immunology and Microbiology, University of Copenhagen, 2200 Copenhagen, Denmark; cvadivel@sund.ku.dk (C.K.V.); mgluud@sund.ku.dk (M.G.); storres@sund.ku.dk (S.T.-R.); labo@ssi.dk (L.B.); awo@sund.ku.dk (A.W.-O.); terkild.buus@sund.ku.dk (T.B.B.); tea@sund.ku.dk (T.K.N.); cmenne@sund.ku.dk (C.M.B.); cge@sund.ku.dk (C.G.); thorkr@sund.ku.dk (T.K.)

2 The Danish National Biobank, Statens Serum Institut, 2300 Copenhagen, Denmark

3 Division of Basal Tumor Biology, Department of Molecular Biology, Umea University, 90187 Umea, Sweden; jenny.persson@umu.se

4 Department of Biomedical Sciences, Malmo University, 21428 Malmo, Sweden

5 Department of Plant and Environmental Sciences, University of Copenhagen, 1871 Frederiksberg, Denmark; atf@plen.ku.dk

* Correspondence: ndum@sund.ku.dk (N.O.); awoetmann@sund.ku.dk (A.W.); Tel.: +45-35327879 (N.O.); +45-35327868 (A.W.)

check for

updates

Citation: Vadivel, C.K.; Gluud, M.; Torres-Rusillo, S.; Boding, L.; Willerslev-Olsen, A.; Buus, T.B.;

Nielsen, T.K.; Persson, J.L.; Bonefeld, C.M.; Geisler, C.; et al. JAK3 Is Expressed in the Nucleus of Malignant T Cells in Cutaneous T Cell Lymphoma (CTCL). Cancers 2021, 13, 280. https://doi.org/10.3390/ cancers 13020280

Received: 15 October 2020 Accepted: 11 January 2021 Published: 14 January 2021

Publisher's Note: MDPI stays neutral with regard to jurisdictional clai$\mathrm{ms}$ in published maps and institutional affiliations.

Copyright: (C) 2021 by the authors. Licensee MDPI, Basel, Switzerland. This article is an open access article distributed under the terms and conditions of the Creative Commons Attribution (CC BY) license (https:// creativecommons.org/licenses/by/ $4.0 /)$.
Simple Summary: JAK3 plays an important role in the pathogenesis of cutaneous T cell lymphoma. JAK3 belongs to the Janus kinase family of receptor-associated tyrosine kinases located in cytoplasm adjacent to the plasma membrane. In this study, we show that JAK3 can also be ectopically expressed in the nucleus in CTCL cell lines and primary cells from CTCL patients. Importantly, JAK3 interacts with the nuclear protein RNA polymerase II and phosphorylates Histone H3. Thus, our data provide first evidence for nuclear expression of JAK3 and interactions with key nuclear proteins in malignant $\mathrm{T}$ cells suggesting a novel non-canonical role in CTCL.

Abstract: Perturbation in JAK-STAT signaling has been reported in the pathogenesis of cutaneous T cell lymphoma (CTCL). JAK3 is predominantly associated with the intra-cytoplasmic part of IL-2R $\gamma \mathrm{C}$ located in the plasma membrane of hematopoietic cells. Here we demonstrate that JAK3 is also ectopically expressed in the nucleus of malignant $\mathrm{T}$ cells. We detected nuclear JAK3 in various CTCL cell lines and primary malignant T cells from patients with Sézary syndrome, a leukemic variant of CTCL. Nuclear localization of JAK3 was independent of its kinase activity whereas STAT3 had a modest effect on nuclear JAK3 expression. Moreover, JAK3 nuclear localization was only weakly affected by blockage of nuclear export. An inhibitor of the nuclear export protein CRM1, Leptomycin B, induced an increased expression of SOCS3 in the nucleus, but only a weak increase in nuclear JAK3. Importantly, immunoprecipitation experiments indicated that JAK3 interacts with the nuclear protein POLR2A, the catalytic subunit of RNA Polymerase II. Kinase assays showed tyrosine phosphorylation of recombinant human Histone $\mathrm{H} 3$ by JAK3 in vitro-an effect which was blocked by the JAK inhibitor (Tofacitinib citrate). In conclusion, we provide the first evidence of nuclear localization of JAK3 in malignant T cells. Our findings suggest that JAK3 may have a cytokinereceptor independent function in the nucleus of malignant $\mathrm{T}$ cells, and thus a novel non-canonical role in CTCL.

Keywords: JAK3; cutaneous T cell lymphoma; Mycosis fungoides; Sézary syndrome; tyrosine kinases 


\section{Introduction}

Cutaneous T cell lymphoma (CTCL) is a haematological cancer where clonally expanded malignant $\mathrm{T}$ cells accumulate in the skin leading to chronically inflamed skin lesions [1-5]. The disease presents with skin patches, plaques and lesions and becomes progressive disease in approximately a third of the patients [5,6]. Mycosis fungoides (MF) and Sézary syndrome (SS) are the two well-studied clinically distinct variants of CTCL [2,5]. MF is the most common form that mainly affects the skin and often has a protracted and relatively indolent disease course, whereas SS is a rare, but highly aggressive, leukemic variant of CTCL with generalized skin involvement [3]. Despite comprehensive research, the aetiology of CTCL remains largely unknown. Single-cell sequencing has revealed a high level of disease heterogeneity - both between patients (inter-patient heterogeneity) and in the individual patient (intra-patient heterogeneity) [7] indicating that individual patients harbour highly heterogeneous populations of malignant $\mathrm{T}$ cells $[7,8]$ which has also been confirmed by immunohistochemistry and analyses of separate lesions derived from the same patient $[9,10]$. Other genetic studies have also indicated that CTCL is a highly heterogeneous disease and is not driven by a single somatic mutation [11,12].

Deregulation of common signaling pathways is a characteristic feature of malignant $\mathrm{T}$ cells and implicated in disease progression [13]. In particular, deregulated Janus Kinase 3 (JAK3) signaling and activation of downstream targets such as STAT3, STAT5, and STAT6 appears to play an important role in cytokine expression, proliferation, and resistance to apoptosis in malignant T cells [14-17]. Aberrant JAK3/STAT activation indirectly impact multiple other signaling pathways through modulators such as microRNAs (miRs) [18]. JAK3/STAT signaling drives the expression of oncogenic miRs such as miR-155, miR-21, miR-93, and miR-214 $[19,20]$ as well as repression of putative tumour suppressors (SATB1, PDCD4, JARID2) in malignant T cells $[18,21,22]$. Interestingly, activating mutations in JAK3 and its substrates STAT3 and STAT5 as well as deletions and/or loss of function of negative regulators such as SOCS1, SOCS3, and HNRNPK have been reported in CTCL [12,23-25]. Moreover, environmental factors such as Staphylococcus aureus can fuel disease activity through an enhanced JAK/STAT activation, cytokine receptor expression, and proliferation of malignant $\mathrm{T}$ cells in situ in patients with severe CTCL. This suggest that a series of different events and factors may converge to trigger deregulated JAK/STAT signaling in malignant $\mathrm{T}$ cells highlighting the key role of JAK3 and downstream effectors in carcinogenesis in CTCL and other T cell malignancies [26-28]. Conventionally, Janus kinases are considered to be members of the class of receptor-associated tyrosine kinases (reviewed in [29]). Surprisingly, recent studies reported on nuclear expression of JAK1 in large B cell lymphoma and JAK2 was shown to function as nuclear tyrosine kinase regulating histone phosphorylation and cellular survival in human haematopoietic stem cells and B cell leukemia cells $[30,31]$. Yet, nothing is known about nuclear functions of JAK3 and to our knowledge no studies so far have reported on nuclear expression and function of Janus kinases in malignant T cells. Accordingly, we investigated the nuclear expression of JAK3 and whether it interacts with nuclear proteins in malignant $\mathrm{T}$ cells.

\section{Results}

As mentioned above, JAK3 is believed to play an important role in the pathogenesis of CTCL. Thus, JAK3 promotes survival and proliferation of malignant $\mathrm{T}$ cells and expression of proto-oncogenes / oncomiRs and cytokines (IL-5, IL-9, IL-13, IL-17F and LTA), some of which are growth factor to malignant $\mathrm{T}$ cells while others modulate the tumour microenvironment (TME) and anti-cancer immunity (Summarized in Table S1). To confirm the relevance of JAK3 inhibition in the present cellular context, MyLa2059 cells were treated with JAK3 inhibitor or vehicle control and the fold change in mRNA expression in vehicleto-JAK3 inhibitor-treated cells is shown confirming that JAK3 regulates expression of these genes in MyLa2059 cells (Table S1).

Nuclear localization of JAK3 has recently been observed in HIV-infected CD4 ${ }^{+} \mathrm{T}$ cells [32] which prompted us to hypothesize that malignant $\mathrm{CD}^{+} \mathrm{T}$ cells from CTCL 
patients may also display ectopic expression and function of JAK3. Accordingly, we performed Western blotting (WB) on isolated cytoplasmic and nuclear extracts from the malignant cell lines MyLa 2000, MyLa 2059, SeAx, and HH. As shown in Figure 1a, JAK3 was expressed in the nucleus of all of four tested malignant cell lines (Figure 1a). We next performed transient knockdown of JAK3 using siRNA against JAK3 to validate the specificity of the anti-JAK3 antibody prior to analysis for nuclear JAK3 expression by immunofluorescence. As shown in Figure $1 \mathrm{~b}$ and Figure S1, siRNA treatment for $48 \mathrm{~h}$ almost completely abolished nuclear JAK3 expression as judged from WB on cytoplasmic and nuclear extracts from the MyLa2059 and MyLa 2000 respectively. In parallel, we performed immunofluorescence in MyLa2059. JAK3 expression was almost completely abolished by siRNA-mediated JAK3 knock-down (Figure 1c) when compared with cells treated with the scrambled siRNA control (Figure 1c). JAK3 was expressed in the nucleus as judged from the merged images of nuclear and JAK3 staining (Figure 1c), and almost completely absent following siRNA mediated JAK3 knockdown (Figure 1c). Quantification of mean fluorescence intensity (MFI) confirmed the nuclear expression of JAK3 in MyLa 2059, which was profoundly inhibited following siRNA mediated JAK3 knockdown (Figure $1 \mathrm{~d}, p<0.0001$ ). We also performed immunofluorescence staining in MyLa 2000 and verified the nuclear expression of JAK3 (Figure S1).

a

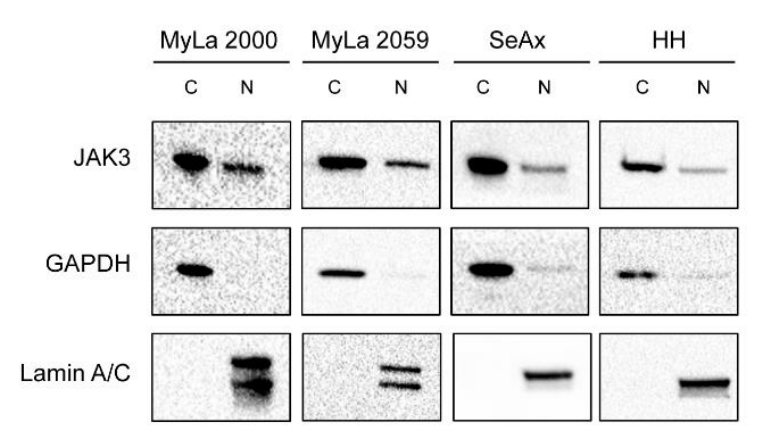

c

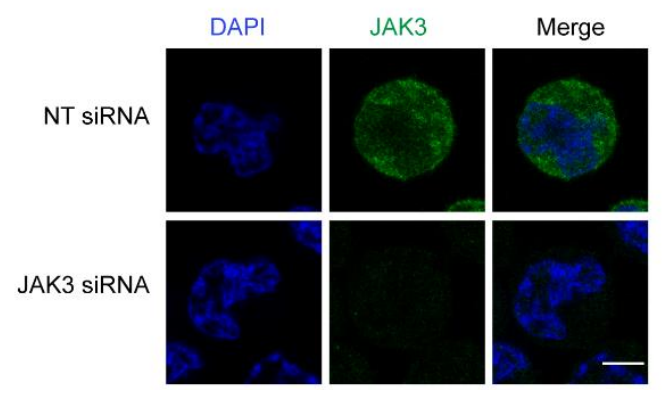

b

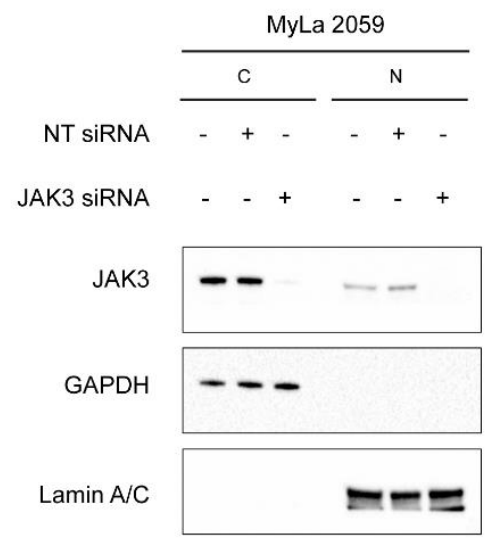

d

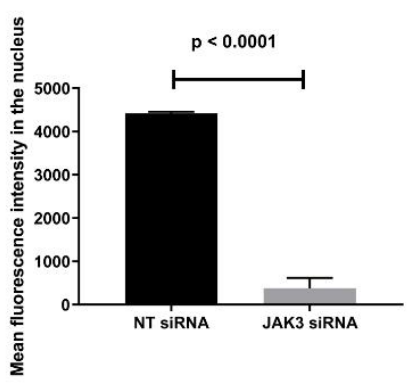

Figure 1. JAK3 is expressed in the nucleus in CTCL cell lines. (a) Immunoblot shows JAK3 expression in the cytoplasmic and nuclear extracts of malignant cell lines MyLa 2000, MyLa 2059, SeAx, and HH. (b) Immunoblot shows low or no expression of JAK3 in the cytoplasmic (C) and nuclear extracts (N) of MyLa 2059 after $48 \mathrm{~h}$ of siRNA mediated knockdown of JAK3. (c) Immunofluorescence (IF) of MyLa 2059 confirming JAK3 expression in the nucleus. Scale bar $=5 \mu \mathrm{m}$. NT siRNA is the non-targeted control siRNA and JAK3 siRNA is the siRNA targeted against JAK3. (d) Mean fluorescence intensity of JAK3 calculated in the nucleus of MyLa 2059 after IF. Error bar represents standard error of mean.

To address whether nuclear JAK3 expression was a common feature of malignant $\mathrm{T}$ cells, we extracted cytoplasmic and nuclear lysates and performed WB using PBMC from patients with SS. Immunoblots showed that JAK3 was expressed in the nuclear 
extracts (Figure 2a) extending our findings above in the malignant $\mathrm{T}$ cell lines. We also performed nuclear and cytoplasmic extraction in PBMC from healthy individuals showing low expression of JAK3 in the nucleus (Figure S2) confirming other studies by Ivan L et al. that healthy T cells may also display nuclear JAK3 expression [32]. Next, we separated $\mathrm{CD}^{+} \mathrm{T}$ cells from PBMC isolated from SS patients and extracted cytoplasmic and nuclear extracts. Immunoblots of lysates show that JAK3 was expressed in the nucleus of CD4 ${ }^{+} \mathrm{T}$ cells isolated from SS patients (Figure 2b). These findings were further substantiated by JAK3 immunofluorescence analysis in primary malignant $\mathrm{T}$ cells from three SS patients (Figure 2c,d).

a

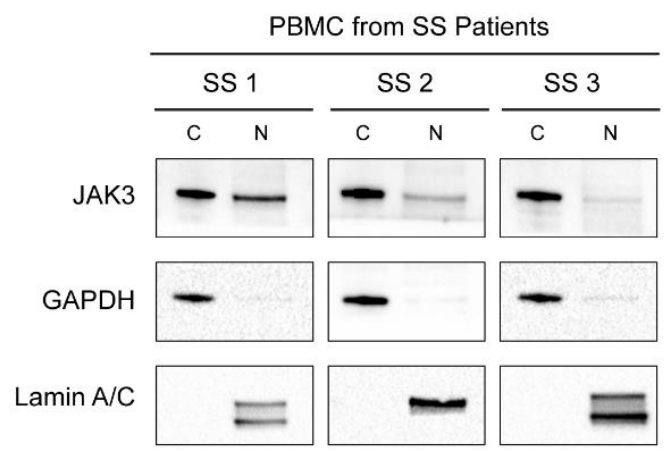

C

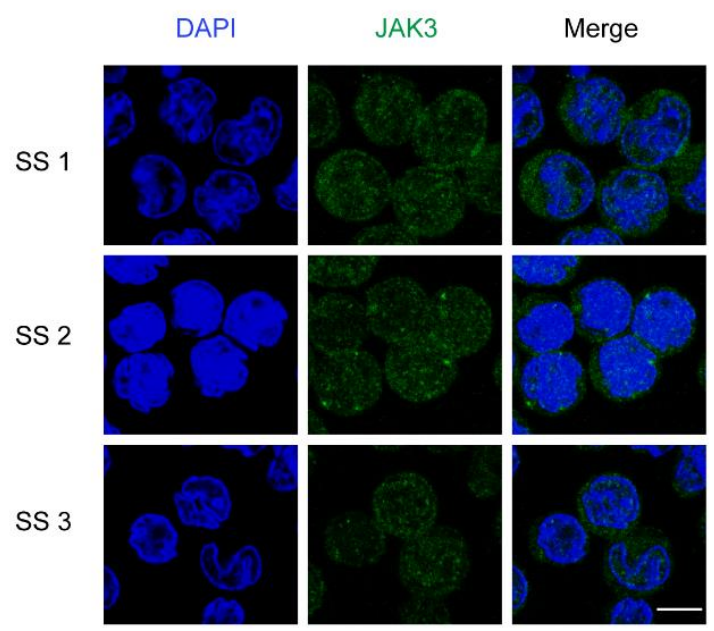

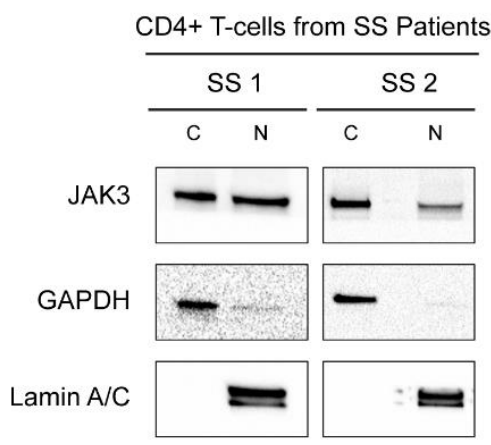

d

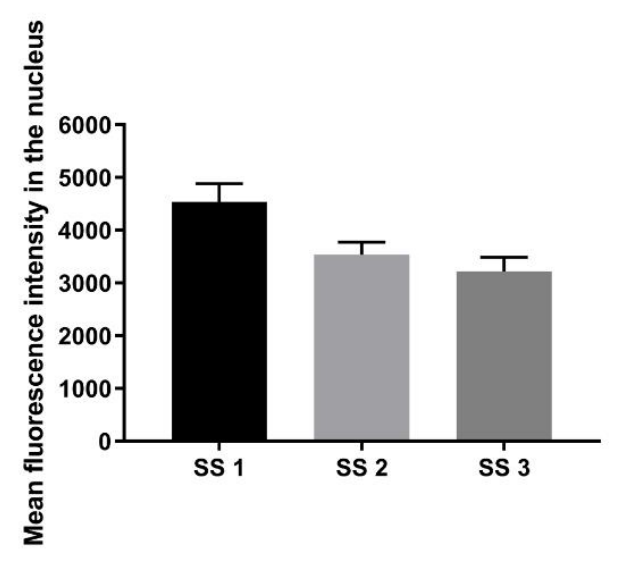

Figure 2. JAK3 is expressed in the nucleus in cells from SS patients. (a) Immunoblot shows JAK3 expression in the cytoplasmic and nuclear extracts of PBMC isolated from SS patients. (b) Immunoblot shows JAK3 expression in the cytoplasmic (C) and nuclear extracts $(\mathrm{N})$ of $\mathrm{CD}^{+} \mathrm{T}$ cells isolated from SS patients. (c) Immunofluorescence (IF) confirming JAK3 expression in the nucleus of $\mathrm{CD}^{+} \mathrm{T}$ cells isolated from SS patients. Scale bar $=5 \mu \mathrm{m}$. (d) Mean fluorescence intensity of JAK3 calculated in the nucleus after IF. Error bar represents standard error of mean. Display settings were adjusted after image analysis using Image $\mathrm{J}$ and the same settings were propagated in all samples.

Once we had confirmed nuclear expression of JAK3 in CTCL, we asked whether JAK3 nuclear expression was affected by JAK3 kinase activity. Accordingly, we inhibited JAK3 activity in malignant $\mathrm{T}$ cell lines with the JAK inhibitor Tofacitinib citrate [33]. As an in vivo read-out of JAK3 kinase activity, we measured STAT3 tyrosine phosphorylation, a key down-stream effect of JAK in malignant T cells [34]. The expression level of JAK3 in the nucleus remained largely unchanged despite inhibition of JAK3 kinase activity, as demonstrated by a profound inhibition of phosphorylated STAT3 (Figure 3a). These find- 
ings suggests that JAK3 kinase activity is not essential for its nuclear expression. Next, we tested the hypothesis that nuclear expression of JAK3 may be influenced by STAT3. To this end, we transiently knocked down STAT3 in MyLa 2000 and MyLa 2059 using siRNA against STAT3, and after $48 \mathrm{~h}$, we isolated cytoplasmic and nuclear extracts prior to WB. STAT3 knockdown strongly inhibited STAT3 expression in both the cytoplasmic and the nuclear fraction whereas the expression of the cytoplasmic house-keeping protein GAPDH and the nuclear protein Lamin A/C was largely unaffected (Figure 3b). STAT3 knockdown induced a modest inhibition of nuclear JAK3 expression (Figure 3b) suggesting that JAK3 expression in the nucleus was partly dependent on STAT3.

a

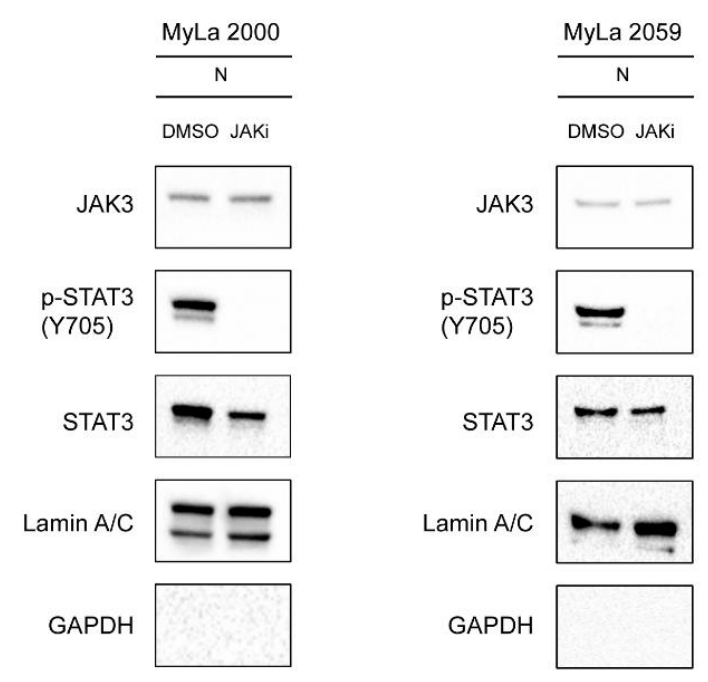

b

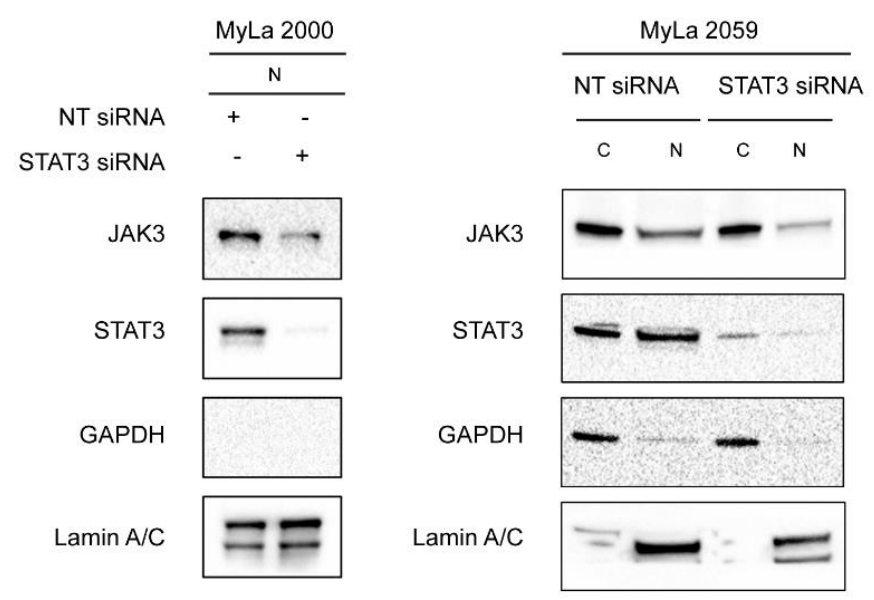

Figure 3. Nuclear localization of JAK3 is independent of its kinase activity and only partly dependent on STAT3. (a) Immunoblot shows JAK3 expression in the nuclear extracts (N) of MyLa 2000 (left) and MyLa 2059 (right) after $24 \mathrm{~h}$ of treatment with $50 \mu \mathrm{M}$ JAK inhibitor, Tofacitinib citrate (CP-690550-10). DMSO is used as a control. JAKi-JAK inhibitor, Tofacitinib citrate (CP-690550-10). (b) Immunoblots of cytoplasmic (C) and/or nuclear (N) lysates shows JAK3 expression in control (NT siRNA) and STAT3 transiently knocked down cells (STAT3 siRNA) in MyLa 2000 (left) and MyLa 2059 (right) after $48 \mathrm{~h}$.

Nuclear expression of STAT3 in malignant T cells is regulated by the ratio of its nuclear import to export, which in turn is regulated by serine/threonine phosphorylation [35]. The PP2A phosphatase inhibitor Calyculin A triggers enhanced nuclear export of STAT3 resulting in a marked decrease in nuclear STAT3 expression in malignant T cells [35]. We ad- 
dressed whether JAK3 was similarly regulated. As expected, Calyculin A inhibited nuclear STAT3 expression but had no inhibitory effect on nuclear expression of JAK3 (Figure 4a) suggesting that nuclear export and expression of JAK3 and STAT3 are regulated differently.

a
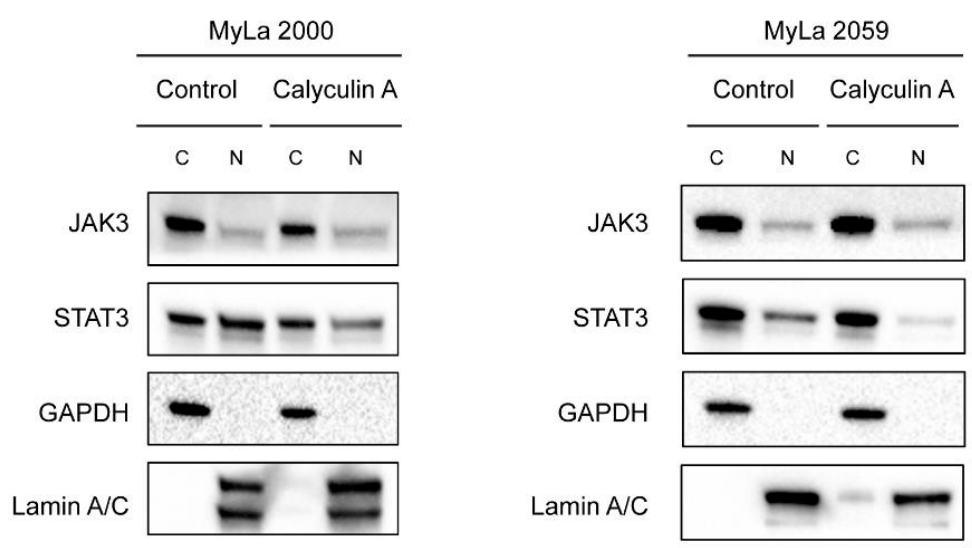

b
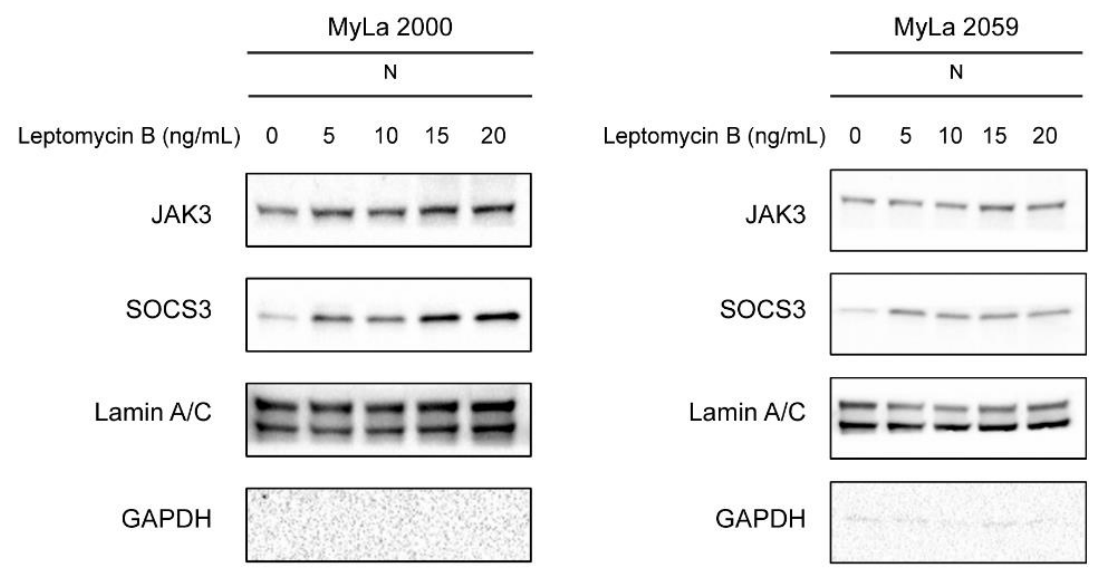

Figure 4. CRM1 inhibitor but not PP2A inhibitor has an effect on nuclear translocation of JAK3. (a) Immunoblot shows JAK3 expression in the cytoplasmic (C) and nuclear (N) extracts of MyLa 2000 (left) and MyLa 2059 (right) after treatment with either DMSO (Control) or $80 \mathrm{nM}$ Calyculin A for $1 \mathrm{~h}$. (b) Immunoblot shows JAK3 expression in the nuclear extracts (N) from MyLa 2000 (left) and MyLa 2059 (right) after treatment with mentioned concentrations (0-20 ng/mL) of Leptomycin B for $3 \mathrm{~h}$.

Nuclear translocation is often mediated through a nuclear localization sequence (NLS), which has been identified in JAK1 and is required for nuclear translocation of JAK1 in hematopoietic cancer cells [36]. We looked for potential NLS sequences in JAK3 but were unable to identify a relevant sequence through NLS mapper [37]. We also analyzed primary amino acid sequence of JAK3 from UniProt [38] for potential nuclear export sequence (NES) [39] and found that the amino acid sequence of JAK3 from 163 to 170 resembles the canonical class 2 leucine-rich NES LXLXXLXL [40]. A bioinformatics NES prediction tool, NetNES [41] also predicted this site in JAK3 as a potential NES. Similarly, the NetNES also predicted a NES sequence corresponding to primary amino acid sequence from 16 to 22 (LDTSLRL) in SOCS3, a regulator of JAK-STAT signaling (reviewed in [42]). The nuclear protein CRM1/Exportin-1 recognises these NES sequences and export the cargo from the nucleus to the cytoplasm (reviewed in [43]). So, we blocked nuclear export protein CRM1 with the inhibitor, Leptomycin B [44], and investigated whether JAK3 accumulated in the nucleus after inhibition of nuclear export. Leptomycin B triggered a weak increase in JAK3 
nuclear expression in MyLa 2059 and a stronger increase in MyLa 2000 cells (Figure 4b). Leptomycin B induced an increase in nuclear expression of SOCS3 in both MyLa 2000 and MyLa 2059 (Figure 4b) indicating that SOCS3 also recruits CRM1 for its nuclear export.

Next, we addressed whether JAK3 interacts with other nuclear proteins. We hypothesized RNA Polymerase II could be a target as JAK3 was shown to interact with RNA Polymerase II in NK/T-cell lymphoma [45]. Accordingly, we performed co-immunoprecipitation (co-IP) in MyLa2000 and MyLa 2059 and found that JAK3 interacts with POLR2A, the catalytic subunit of RNA Polymerase II (Figure 5a). We verified this interaction by reverse co-IP (Figure 5a) supporting the hypothesis that JAK3 may play a role in nuclear signaling in malignant T cells. As JAK1 and JAK2 modulate epigenetic regulation of gene transcription through tyrosine phosphorylation of the histone protein $\mathrm{H} 3$ in leukemic- and B cell lymphoma- cell lines $[30,31]$, we performed in vitro kinase assays to address whether JAK3 was also able to phosphorylate Histone H3. As shown in Figure 5b, recombinant JAK3 induced phosphorylation of recombinant Histone $\mathrm{H} 3$, an effect that was inhibited by the JAK inhibitor Tofacitinib citrate. These findings indicated that JAK3 (like JAK1 and JAK2) has the capacity to phosphorylate Histone H3. Further studies are warranted to address whether JAK3 associates with and phosphorylate Histone $\mathrm{H} 3$ in vivo and how this might modulate epigenetic regulation and transcription in malignant $\mathrm{T}$ cells.

a

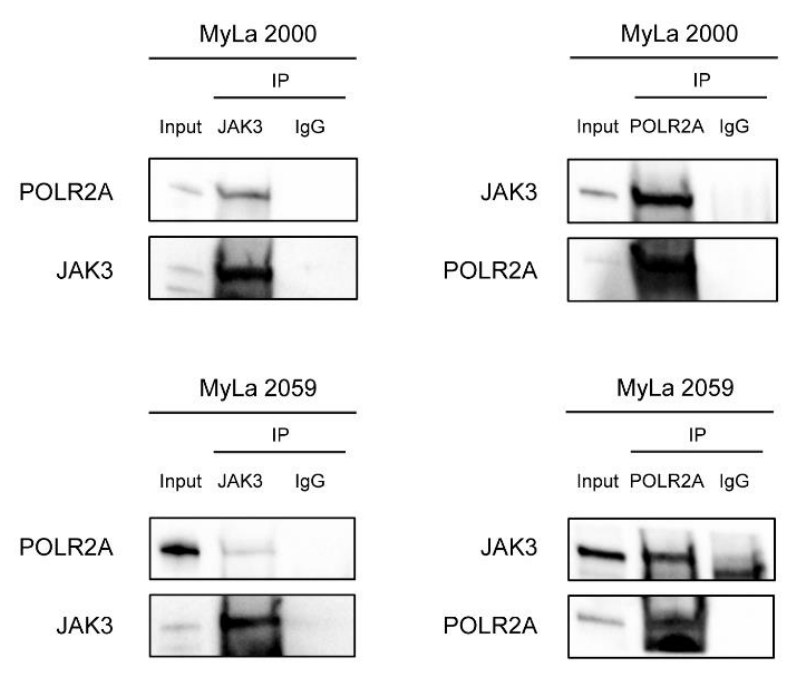

b

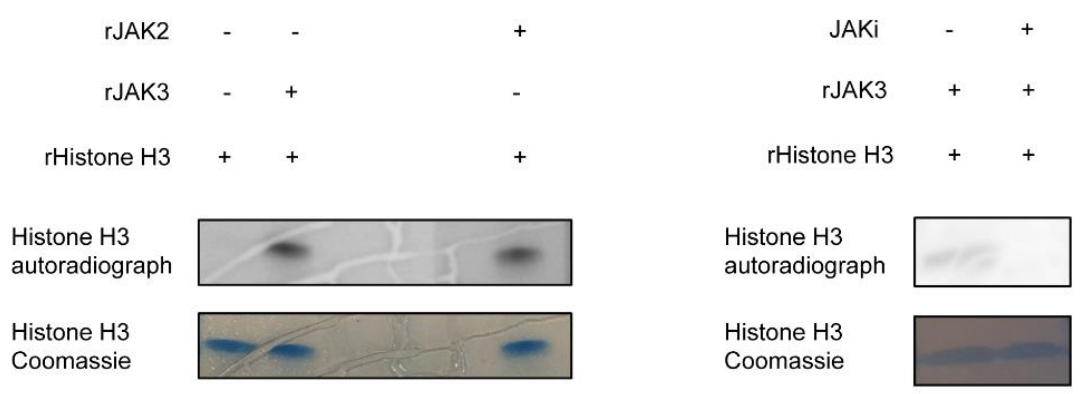

Figure 5. JAK3 interacts with RNA Polymerase II in MyLa cells. (a) Immunoblots after coimmunoprecipitation assay shows JAK3 interacts with POLR2A in MyLa 2000 (up) and MyLa 2059 (down). (b) Autoradiograph shows in vitro tyrosine phosphorylation of recombinant human Histone $\mathrm{H} 3$ by recombinant human JAK3 (left) and the phosphorylation is inhibited by pre-incubating the kinase, JAK3, with $100 \mathrm{nM}$ JAK inhibitor Tofacitinib citrate (JAKi) for 30 min (right side panel). Coomassie staining of the gel shows Histone $\mathrm{H} 3$ in all the samples. Recombinant human JAK2 is used as a positive control for the kinase assay. 


\section{Discussion}

JAK3 belongs to the Janus kinase family of tyrosine kinases, which are believed to play a key role in oncogenesis and disease progression in several cancers including hematological malignancies [46-48]. Multiple events and mechanisms including activating mutations in JAKs and STATs have been implicated in the oncogenic role of JAK/STAT signaling $[49,50]$. Interestingly, mutations in the pseudokinase domain of a particular JAK have been shown to transactivate an opposing different partnering JAK family member [51,52], demonstrating that constitutive activation of JAK3 may also be due to a mutation in a different JAK family member. In addition, mutations of cytokine- and growth factor receptors such as IL7Ra can result in IL-7 receptor hypersensitivity leading to elevated JAK3 activation [53] indicating multilevel control of JAK activation (and deregulation) in cancer.

JAK3 is believed to play a key role in the pathogenesis in CTCL but it is not fully understood what drives aberrant JAK3 in malignant T cells. JAK3 mutations have been described in a small number of CTCL patients indicating a direct role of mutated JAK3 in driving oncogenesis in these patients [54]. Mutations and functional deficiencies in negative regulators of JAK3/STAT3 have also been implicated in the constitutive JAK3/STAT3 signaling in malignant $T$ cells $[17,55]$. Nuclear expression of JAKs other than JAK3 (such as JAK1, JAK2, and TYK2) have previously been reported in other malignancies and new unexpected-so-called non-canonical-functions (like histone tyrosine phosphorylation) have been assigned to these JAKs [30,36,56]. In contrast, little is known about nuclear expression and function of JAK3 in malignant $\mathrm{T}$ cells and their healthy counterpart. Here, we provide first evidence for nuclear expression of JAK3 in malignant $\mathrm{T}$ cells. We found JAK3 in the nucleus of malignant $\mathrm{T}$ cell lines and primary $\mathrm{T}$ cells isolated from peripheral blood of patients with SS, indicating that nuclear JAK3 expression is a common feature of malignant $\mathrm{T}$ cells. Whereas nuclear JAK3 expression has not previously been reported in malignant $\mathrm{T}$ cells, others have found nuclear JAK3 expression in $\mathrm{CD} 4^{+} \mathrm{T}$ cells from HIV infected patients [32] and in non-hematopoietic cells following exposure of high concentration of IL-2 [57]. These findings suggest that nuclear expression of JAK3 is not an intrinsic feature of malignant $T$ cells, but rather a common phenomenon related to cellular activation. This conclusion is in agreement with other findings indicating a non-canonical, nuclear function of JAKs in epigenetic regulation of transcription [30,31].

As JAKs are not small molecules, they would be expected to have an NLS in order to translocate to the nucleus. Indeed, JAK1 is known to have an NLS sequence required for transport to the nucleus [36]. Using the NLS mapper [37], we were unable to identify NLS in JAK3 suggesting that other mechanisms are involved in nuclear translocation of JAK3. We hypothesized that nuclear translocation of JAK3 might be coupled with translocation of other signaling molecules, e.g., STAT3, which appear to be constantly transported into and out of the nucleus in malignant $\mathrm{T}$ cells [35] and accommodate nuclear translocation of other signaling molecules such as NF-kB [58]. In support, STAT3 knockdown by siRNA partly inhibited nuclear expression of JAK3 suggesting that nuclear translocation of JAK3 may partly be coupled with STAT3. Interestingly, nuclear JAK3 localization seemed to be independent of JAK kinase activity and tyrosine phosphorylation of STAT3 as inhibition of kinase activity and STAT3 phosphorylation by Tofacitinib citrate had no effect. This is consistent with the finding that JAK1 activation is not required for its nuclear import [36]. Although it may seem counterintuitive, tyrosine phosphorylation of STAT3 is not essential for its translocation and co-transportation of NF-kB to the nucleus [59]. The present findings suggest that a similar mechanism may be involved in STAT3-mediated translocation of JAK3.

The inhibitor of nuclear export protein CRM1, Leptomycin B, is known to regulate STAT3 expression in the nucleus in certain non-hematopoietic cells [60]. Since STAT3 knockdown had a modest effect on nuclear localization of JAK3 in malignant cells, and because we predicted a potential NES sequence in JAK3, we addressed whether Leptomycin $B$ regulated JAK3 nuclear expression like STAT3. Indeed, Leptomycin B enhanced JAK3 nuclear expression - most profoundly in MyLa2000 cells and weakly in MyLa 2059 cells- 
supporting the idea that nuclear localization of JAK3 was, at least partly, regulated via CRM1. Of notice, nuclear SOCS3 expression was also increased upon CRM1 inhibition, which was in keeping with our identification of a putative NES sequence in SOCS3. Thus, it appears that all members of the JAK3/STAT3/SOCS3 signaling pathway are regulated by CRM1 implying that JAK3 and SOCS3 may also play a role in nuclear signaling in malignant $\mathrm{T}$ cells, which has not been described before. Interestingly, SOCS1 was recently shown to regulate nuclear activity of NF-kB [61] suggesting that SOCS proteins are indeed regulators of nuclear signaling. It is well known that malignant $\mathrm{T}$ cells display an ectopic expression of SOCS3, which provides resistance to inhibition by interferon- $\alpha$ [62]. It is also clear that SOCS3 expression is driven by aberrant JAK3/STAT3 activation in malignant T cells [62], whereas a nuclear expression and function of SOCS3 has never been reported in CTCL. Our finding that nuclear JAK3 expression was unaffected by PP2A blockage, which triggered enhanced export of STAT3 as previously reported [35] and confirmed here, suggests that nuclear export of JAK3 in malignant T cells is not regulated in the same manner as STAT3 in relation to PP2A despite the shared regulation by CRM1. CRM1 specific inhibitors are being used in clinical trials as a target for number of cancer therapies including non-Hodgkin lymphomas $([63,64]$ and reviewed in $[65,66])$. Of interest, a CRM1 inhibitor showed anticancer activity in a JAK3 mutant mouse model for T-ALL $[67,68]$ suggesting the highly interesting possibility that shifting the dynamics of nuclear import/export and the balance between nuclear and cytoplasmic JAK3 might also be a novel potential target for therapy in CTCL. Accordingly, CRM1 inhibitors could be of interest to test as novel remedies for inhibition of malignant T cells in CTCL as it regulates the activity of JAK3/STAT3/SOCS3, a key signaling pathway in malignant transformation in CTCL [17].

As JAK3 is expressed in the nucleus, we investigated the nuclear function of JAK3 in CTCL. Studies have shown that both JAK1 and JAK2 phosphorylates Histone H3 on Tyr $41[30,31]$. We performed in vitro kinase assay and found that recombinant JAK3 phosphorylates recombinant Histone $\mathrm{H} 3$ and this phosphorylation was blocked in the presence of JAK inhibitor Tofacitinib citrate. Due to lack of phospho-tyrosine specific antibody against Histone $\mathrm{H} 3$, we could not verify the in vivo phosphorylation. As well, we performed co-immunoprecipitation assays and showed that JAK3 interacts with POLR2A, the biggest and catalytic active subunit of RNA Polymerase II. This is consistent with a previous finding by J Yan et al. that JAK3 interacts with RNA Polymerase II in NK/T-cell lymphoma [45]. They proposed that the interaction between JAK3 and RNA Polymerase II was a result of JAK3 interaction with the Histone methyl transferase EZH2, however, we could not find JAK3 interaction with EZH2 in CTCL (data not shown). At present, it remains to be investigated whether nuclear expression of JAK3 involves interaction with POLR2A in healthy, non-malignant $\mathrm{T}$ cells or whether this interaction is a unique, cancer-associated feature of malignant $\mathrm{T}$ cells.

In conclusion, we provide first evidence that JAK3 is expressed in the nucleus of malignant $\mathrm{T}$ cells and interacts with a nuclear protein RNA Polymerase II which supports a non-canonical role of JAK3 in CTCL.

\section{Materials and Methods}

\subsection{Cell Lines, Primary Cells and Cell Culture}

The cell lines used in the study were previously described [69-72]. Myla 2059 and Myla 2000 were cultured in RPMI-1640 medium (Sigma, St. Louis, MO, USA \#R2405) supplemented with 10\% fetal bovine serum (FBS) (Biological Industries, Cromwell, CT, USA \#04-007-1A) and 1\% Penicillin/Streptomycin (Sigma, \#P7539). HH cells were cultured in RPMI-1640 medium supplemented with 20\% FBS and 1\% Penicillin/Streptomycin. SeAx, was cultured in RPMI-1640 medium supplemented with 10\% human serum (HS) (Copenhagen University Hospital Blood Bank), 1\% Penicillin/Streptomycin and $1000 \mathrm{U} / \mathrm{mL}$ human IL-2 (Novartis, Basel, Switzerland \#004184). Cells were maintained in an incubator at $37^{\circ} \mathrm{C}$ with $5 \% \mathrm{CO}_{2}$ and were replenished with fresh medium every two days. Isolation of PBMC from SS patients was done by Ficoll-based density-gradient centrifugation. $\mathrm{CD}^{+} \mathrm{T}$ 
cells were isolated from PBMC using EasySep ${ }^{\mathrm{TM}}$ Human CD4 ${ }^{+}$T Cell Isolation Kit (StemCell, Vancouver, BC, Canada \#17952) by following the manufacturer's protocol. Necessary approvals were obtained from the Committee on Health Research ethics (H-16025331) prior to using SS patients' samples and the work was performed in accordance with the Declaration of Helsinki.

\subsection{Cell Fractionation and Western Blotting}

Cytoplasmic and nuclear lysates were extracted using NE-PER ${ }^{\mathrm{TM}}$ Nuclear and Cytoplasmic Extraction Reagents (Thermo Fisher, Waltham, MA, USA \#78835) as per manufacturer's protocol with some modifications. In order to reduce the contamination of the nuclear extract, an additional washing of the nuclear pellet with ice cold Phosphate buffered saline (PBS) was performed after isolating the cytoplasmic extract. Preparation of whole cell lysates, SDS-PAGE and western blotting were described elsewhere [34]. Equal amounts of protein were loaded unless mentioned otherwise.

\subsection{Transient Transfection}

For transient transfections, 2 million cells were re-suspended in a transfection reagent (Mirus Bio, Madison, WI, USA \#MIR50111) with $0.2 \mu \mathrm{M}$ siRNA against either JAK3 (Dharmacon, Lafayette, CO, USA \#L-003147-00-0005) or STAT3 (Dharmacon, \#L-003544-00-0005) or non-targeting control (Dharmacon, \#D-001810-01-20) and were transfected using the program A-30 on the Amaxa Nucleofector (Lonza, Basel, Switzerland). Cells were cultured for $48 \mathrm{~h}$ after transfection and used for experiments.

\subsection{Immunofluorescence}

Cells were stained on $18 \mathrm{~mm}$ diameter coverslips (1.5 thickness) for immunofluorescence. Briefly, 1:1000 dilution of poly-L-lysine $(1 \mathrm{mg} / \mathrm{mL})$ solution (Sigma, \#P2636) was coated on the coverslips for $30 \mathrm{~min}$ and were washed once with PBS. 3 million cells were re-suspended in PBS and were added and dried on top of the coated coverslips for $20 \mathrm{~min}$. Cells were fixed with $2 \%$ Paraformaldehyde solution for $15 \mathrm{~min}$, washed gently (three times with PBS for five minutes each) and then permeabilised with ice-cold $100 \%$ Methanol (Sigma, \#34860) at $-20{ }^{\circ} \mathrm{C}$ for $12 \mathrm{~min}$. Cells were washed and blocked with 5\% Bovine Serum Albumin (Sigma, \#A2153) for an hour at room temperature. Primary antibody (antiJAK3) was added and incubated for an hour at room temperature. Cells were washed three times with PBS and then secondary antibody (goat anti-rabbit Alexa Fluor 488 (Thermo Fisher, \#A-11034)) was added at a dilution of 1:700 and incubated for an hour at room temperature. Cells were washed again and then incubated with DAPI (Sigma, \#D9542) (1:500 dilution) for $10 \mathrm{~min}$. Coverslips containing cells were mounted on a glass slide (1.5 thickness) using a mounting medium (Thermo Fisher, \#S36967), stored at $4{ }^{\circ} \mathrm{C}$ until imaging. Cells were then imaged using 63x Plan-Apochromat oil 1.4 numerical aperture (NA) objective of Zeiss LSM710 confocal microscope (Carl Zeiss AG, Oberkochen, Germany).

After immunofluorescence, approximately, 50 randomly chosen cells per treatment per experiment were analysed with Zen Black software (Carl Zeiss AG). The cytoplasm and the nucleus were segmented using Zen Intellesis, an automated intelligent image segmentation feature. Mean fluorescence intensity of JAK3 in the nucleus was then measured and unpaired t-tests were performed to determine statistical significance using Graphpad Prism software (GraphPad, San Diego, CA, USA).

\subsection{Tofacitinib Citrate Treatment}

For JAK inhibition, cells were cultured for $24 \mathrm{~h}$ in a 12 well plate treated with $50 \mu \mathrm{M}$ Tofacitinib citrate (CP-690550-10) (Sigma, \#PZ0017) for both MyLa 2059 and MyLa 2000. DMSO (Sigma, \#D8418) was used as a control to treat cells without Tofacitinib citrate. 


\subsection{Calyculin A Treatment}

MyLa cells were cultured for $24 \mathrm{~h}$ and treated with $80 \mathrm{nM}$ Calyculin A (Enzo Life Sciences, Farmingdale, NY, USA \#BML-EI192-0025) or DMSO (Control) for $1 \mathrm{~h}$ and then, cytoplasmic and nuclear extraction was performed.

\subsection{Leptomycin B Treatment}

To inhibit nuclear export protein CRM1, Leptomycin B solution (Sigma, \#L2913) was used. MyLa cells were cultured for $24 \mathrm{~h}$ in a 12 well plate and then cells were treated with or without Leptomycin B at concentration ranging between 5 to $20 \mathrm{ng} / \mathrm{mL}$ for $3 \mathrm{~h}$. After $3 \mathrm{~h}$, cytoplasmic and nuclear fractions were extracted.

\subsection{Co-Immunoprecipitation}

For co-immunoprecipitation (co-IP), Pierce ${ }^{\mathrm{TM}}$ Protein A Magnetic Beads (Thermo Fisher, \#88845) were used and the experiments were performed according to the manufacturer's protocol with slight modifications. Briefly, pre-cleared whole cell lysates were incubated overnight with primary antibody at $4{ }^{\circ} \mathrm{C}$ with constant mixing. Then, prewashed protein $\mathrm{A}$ beads were added to the antigen-antibody complex and mixed at room temperature for an hour. The antigen-antibody complex bound beads were separated from the mix using the DynaMag ${ }^{\mathrm{TM}}$-2 Magnet (Thermo Fisher, \#12321D) and were washed three times with Tris-buffered Saline (TBS) containing 0.01\% Tween-20 (Sigma, \#822184). The beads were washed once with sterile water. Then bound proteins were eluted by mixing beads with $2 \times$ Laemmli SDS sample buffer and were denaturized at $100{ }^{\circ} \mathrm{C}$ for $10 \mathrm{~min}$ in a heat block. SDS-PAGE and western blotting experiments were then performed.

\subsection{Radioactive In Vitro Kinase Assay}

For in vitro kinase assay, $1 \mathrm{ng}$ of human recombinant JAK3 active protein (Sigma, \#14-629), $1 \mathrm{ng}$ of human recombinant JAK2 active protein (Sigma, \#14-640) and $2 \mu \mathrm{g}$ of human recombinant Histone H3 (Sigma, \#14-494) were used. Briefly, the kinase (JAK2 or JAK3) and the substrate (Histone H3) were re-suspended in a kinase buffer $(20 \mathrm{mM}$ TRIS-HCl pH 7.5, $5 \mathrm{mM} \mathrm{MgCl} 2,5 \mathrm{mM} \mathrm{MnCl}_{2}, 1 \mu \mathrm{M}$ cold ATP) containing $5 \mu \mathrm{Ci} \gamma-{ }^{32} \mathrm{P}$ labelled ATP (Perkin Elmer, Waltham, MA, USA \#NEG002A100UC) and were incubated at $37^{\circ} \mathrm{C}$ for $30 \mathrm{~min}$. The reaction was stopped by adding Laemmli SDS sample buffer and the samples were kept on ice immediately. For inhibition of JAK3, $100 \mathrm{nM}$ Tofacitinib citrate was pre-incubated with the kinase for $30 \mathrm{~min}$ at room temperature. The kinase and the substrate were separated by running samples on 4-20\% SDS-PAGE gel (BioRad, Hercules, CA, USA) followed by staining gel with Coomassie Brilliant blue (BioRad, \#1610786). The gel was de-stained, dried, and kept in contact with storage phosphor image screen (GE Lifesciences, Marlborough, MA, USA) and the screen was visualized in a Typhoon Phosphorimager (GE Lifesciences).

\subsection{Antibodies}

JAK3-1:1000 (Cell Signaling Technology, Danvers, MA, USA \#8827), JAK3-1:1000 for western blotting and 1:500 for immunofluorescence (Abcam, Cambridge, UK \#ab45141), JAK3-1:100 for co-IP (Santa Cruz Biotechnology, Dallas, TX, USA \#sc-513), JAK3-1:1000 used for western blotting followed by co-IP (Novus Biologicals, Centennial, CO, USA \#NBP2-37737), p-STAT3 (Y705)-1:1000 (Cell Signaling Technology, \#9145), GAPDH-1:10,000 (Santa Cruz Biotechnology, \#sc-32233), Lamin A/C-1:1000 (Cell Signaling Technology, \#2032), POLR2A-1:1000 (BioLegend, San Diego, CA, USA \#664906), anti-mouse HRP-1:2000 (Agilent Dako, Glostrup, Denmark \#P044701-2), anti-rabbit HRP-1:1000 (Agilent Dako, \#P044801-2), Isotype controls-rabbit IgG (Cell signaling Technology, \#3900) and mouse IgG2A (R\&D Systems, Minneapolis, MN, USA \#MAB0031). 


\section{Conclusions}

In this study, we provide first evidence that JAK3 is expressed in the nucleus of primary malignant $\mathrm{T}$ cells and $\mathrm{T}$ cell lines from patients with in CTCL. Nuclear translocation of JAK3 was independent of its kinase activity and the nuclear import and export of JAK3 was regulated differently from other members of the JAK/STAT/SOCS signaling cascade. Importantly, JAK3 interacts with the nuclear protein POLR2A, the catalytic subunit of RNA Polymerase II and kinase assays showed tyrosine phosphorylation of recombinant human Histone H3 by JAK3 in vitro. These results suggest that JAK3 may have a novel, non-canonical role in the nucleus in malignant cells.

Supplementary Materials: The following are available online at https:/ / www.mdpi.com/2072-669 4/13/2/280/s1, Figure S1: JAK3 expression in MyLa 2000. Figure S2: JAK3 expression in healthy individuals. Figure S3: Immunoblots corresponding to Figures 1 and 2, Figure S4: Immunoblots corresponding to Figures 3 and 4. Figure S5: Immunoblots corresponding to Figure 5, Figures S1 and S2. Table S1: JAK3 regulated genes in MyLa 2059. Table S2: Relative expression of JAK3, Table S3: Relative expression of STAT3, Table S4: Relative expression of SOCS3. Video S1: 3-dimensional view from top to bottom of a single cell after JAK3 immunofluorescence staining in MyLa 2059 corresponding to Figure 1c. Video S2-S4: 3-dimensional view from top to bottom of a single cell after JAK3 immunofluorescence staining in SS patient 1 (Video S2), SS patient 2 (Video S3), and SS patient 3 (Video S4) corresponding to Figure 2c. The videos were made using Amira (Thermo Fisher).

Author Contributions: Conceptualization: C.K.V., N.O. and A.W.; methodology: C.K.V., N.O., A.W., T.K., A.T.F., M.G., S.T.-R., L.B., A.W.-O., T.B.B. and T.K.N.; investigation: C.K.V.; validation: C.K.V.; Formal analysis: C.K.V.; project administration: C.K.V., N.O. and A.W.; resources: A.T.F., J.L.P., C.M.B. and C.G.; supervision: N.O., A.W., T.K. and A.T.F.; Funding acquisition: N.O.; writing—original draft: C.K.V.; writing - review and editing: all authors. All authors have read and agreed to the published version of the manuscript.

Funding: This research was funded by LEO Foundation, The Danish Cancer Society (Kræftens Bekæmpelse), the Fight Cancer Program (Knæk Cancer), Novo Nordisk Research Foundation, Novo Nordic Foundation Tandem Program (grant number NNF14OC0012345), Lundbeck Foundation (A.W.-O.), The Danish Council for Independent Research (Danmarks Frie Forskningsfond, 2 project grants for N.O., a Sapera Aude Talent Grant (DFF-4092-00122) for T.K.), Dansk Kræftforsknings Fond and Alfonso Martín Escudero Foundation (S.T.-R.).

Institutional Review Board Statement: The study was conducted according to the guidelines of the Declaration of Helsinki and approved by the Committee on Health Research Ethics (H-16025331).

Informed Consent Statement: Informed consent was obtained from all the patients involved in the study.

Data Availability Statement: The data presented in this study are available in the manuscript and in the Supplementary Materials.

Acknowledgments: We would like to acknowledge the patients and healthy donors who donated blood and the team at the Bispebjerg hospital for obtaining the blood samples. We also acknowledge the Core Facility for Integrated Microscopy, Faculty of Health and Medical Sciences, University of Copenhagen, for their assistance with immunofluorescence studies.

Conflicts of Interest: Niels Odum has an advisory consultant honorarium from Micreos human Health B.V., The Hague, The Netherlands, and Almirall, Barcelona, Spain. All other authors declare no potential conflicts of interest.

\section{References}

1. Hristov, A.C.; Tejasvi, T.; Wilcox, R.A. Mycosis fungoides and Sezary syndrome: 2019 update on diagnosis, risk-stratification, and management. Am. J. Hematol. 2019, 94, 1027-1041. [CrossRef] [PubMed]

2. Girardi, M.; Heald, P.W.; Wilson, L.D. The Pathogenesis of Mycosis Fungoides. N. Engl. J. Med. 2004, 350, 1978-1988. [CrossRef] [PubMed]

3. Kim, E.J;; Hess, S.; Richardson, S.K.; Newton, S.; Showe, L.C.; Benoit, B.M.; Ubriani, R.; Vittorio, C.C.; Junkins-Hopkins, J.M.; Wysocka, M.; et al. Immunopathogenesis and therapy of cutaneous T cell lymphoma. J. Clin. Investig. 2005, 115, 798-812. [CrossRef] 
4. Berger, C.L.; Warburton, D.; Raafat, J.; LoGerfo, P.; Edelson, R.L. Cutaneous T-cell lymphoma: Neoplasm of T cells with helper activity. Blood 1979, 53, 642-651. [CrossRef] [PubMed]

5. Krejsgaard, T.; Lindahl, L.M.; Mongan, N.P.; Wasik, M.A.; Litvinov, I.V.; Iversen, L.; Langhoff, E.; Woetmann, A.; Odum, N. Malignant inflammation in cutaneous T-cell lymphoma-a hostile takeover. Semin. Immunopathol. 2017, 39, 269-282. [CrossRef]

6. Scarisbrick, J.J.; Kim, Y.H.; Whittaker, S.J.; Wood, G.S.; Vermeer, M.H.; Prince, H.M.; Quaglino, P. Prognostic factors, prognostic indices and staging in mycosis fungoides and Sézary syndrome: Where are we now? Br. J. Dermatol. 2014, 170, $1226-1236$. [CrossRef]

7. Buus, T.B.; Willerslev-Olsen, A.; Fredholm, S.; Blümel, E.; Nastasi, C.; Gluud, M.; Hu, T.; Lindahl, L.M.; Iversen, L.; Fogh, H.; et al. Single-cell heterogeneity in Sézary syndrome. Blood Adv. 2018, 2, 2115-2126. [CrossRef]

8. Gaydosik, A.M.; Tabib, T.; Geskin, L.J.; Bayan, C.A.; Conway, J.F.; Lafyatis, R.; Fuschiotti, P. Single-Cell Lymphocyte Heterogeneity in Advanced Cutaneous T-cell Lymphoma Skin Tumors. Clin. Cancer Res. 2019, 25, 4443-4454. [CrossRef]

9. Hu, T.; Krejsgaard, T.; Nastasi, C.; Buus, T.B.; Nansen, A.; Hald, A.; Spee, P.; Nielsen, P.R.; Blümel, E.; Gluud, M.; et al. Expression of the Voltage-Gated Potassium Channel Kv1.3 in Lesional Skin from Patients with Cutaneous T-Cell Lymphoma and Benign Dermatitis. Dermatology 2020, 236, 123-132. [CrossRef]

10. Iyer, A.; Hennessey, D.; O'Keefe, S.; Patterson, J.; Wang, W.; Wong, G.K.; Gniadecki, R. Branched evolution and genomic intratumor heterogeneity in the pathogenesis of cutaneous T-cell lymphoma. Blood Adv. 2020, 4, 2489-2500. [CrossRef]

11. Choi, J.; Goh, G.; Walradt, T.; Hong, B.S.; Bunick, C.G.; Chen, K.; Bjornson, R.D.; Maman, Y.; Wang, T.; Tordoff, J.; et al. Genomic landscape of cutaneous T cell lymphoma. Nat. Genet. 2015, 47, 1011-1019. [CrossRef] [PubMed]

12. Da Silva Almeida, A.C.; Abate, F.; Khiabanian, H.; Martinez-Escala, E.; Guitart, J.; Tensen, C.P.; Vermeer, M.H.; Rabadan, R.; Ferrando, A.; Palomero, T. The mutational landscape of cutaneous T cell lymphoma and Sézary syndrome. Nat. Genet. 2015, 47, 1465-1470. [CrossRef] [PubMed]

13. Ødum, N. Deregulated signalling and inflammation in cutaneous T-cell lymphoma. Br. J. Dermatol. 2020, 182, 16-17. [CrossRef] [PubMed]

14. Netchiporouk, E.; Litvinov, I.V.; Moreau, L.; Gilbert, M.; Sasseville, D.; Duvic, M. Deregulation in STAT signaling is important for cutaneous T-cell lymphoma (CTCL) pathogenesis and cancer progression. Cell Cycle 2014, 13, 3331-3335. [CrossRef]

15. Gaydosik, A.M.; Queen, D.S.; Trager, M.H.; Akilov, O.E.; Geskin, L.; Fuschiotti, P. Genome-wide transcriptome analysis of the STAT6-regulated genes in advanced-stage cutaneous T-cell lymphoma. Blood 2020, 136, 1748-1759. [CrossRef]

16. Geskin, L.J.; Viragova, S.; Stolz, D.B.; Fuschiotti, P. Interleukin-13 is overexpressed in cutaneous T-cell lymphoma cells and regulates their proliferation. Blood 2015, 125, 2798-2805. [CrossRef]

17. Seffens, A.; Herrera, A.; Tegla, C.; Buus, T.B.; Hymes, K.B.; Ødum, N.; Geskin, L.J.; Koralov, S.B. STAT3 Dysregulation in Mature T and NK Cell Lymphomas. Cancers 2019, 11, 1711. [CrossRef]

18. Gluud, M.; Willerslev-Olsen, A.; Gjerdrum, L.M.R.; Lindahl, L.M.; Buus, T.B.; Andersen, M.H.; Bonefeld, C.M.; Krejsgaard, T.; Litvinov, I.V.; Iversen, L.; et al. MicroRNAs in the Pathogenesis, Diagnosis, Prognosis and Targeted Treatment of Cutaneous T-Cell Lymphomas. Cancers 2020, 12, 1229. [CrossRef]

19. Gluud, M.; Fredholm, S.; Blümel, E.; Willerslev-Olsen, A.; Buus, T.B.; Nastasi, C.; Krejsgaard, T.; Bonefeld, C.M.; Woetmann, A.; Iversen, L.; et al. MicroRNA-93 Targets p21 and Promotes Proliferation in Mycosis Fungoides T Cells. Dermatology 2020. [CrossRef]

20. van der Fits, L.; van Kester, M.S.; Qin, Y.; Out-Luiting, J.J.; Smit, F.; Zoutman, W.H.; Willemze, R.; Tensen, C.P.; Vermeer, M.H. MicroRNA-21 expression in CD4+ T cells is regulated by STAT3 and is pathologically involved in Sézary syndrome. J. Investig. Dermatol. 2011, 131, 762-768. [CrossRef]

21. Fredholm, S.; Willerslev-Olsen, A.; Met, Ö.; Kubat, L.; Gluud, M.; Mathiasen, S.L.; Friese, C.; Blümel, E.; Petersen, D.L.; Hu, T.; et al. SATB1 in Malignant T Cells. J. Investig. Dermatol. 2018, 138, 1805-1815. [CrossRef] [PubMed]

22. Herrera, A.; Fredholm, S.; Cheng, A.; Mimitou, E.P.; Seffens, A.; Bar-Natan, M.; Sun, A.; Latkowski, J.A.; Willerslew-Olsen, A.; Buus, T.B.; et al. Low SATB1 Expression Promotes IL-5 and IL-9 Expression in Sézary Syndrome. J. Investig. Dermatol. 2020, 140, 713-716. [CrossRef] [PubMed]

23. Kiel, M.J.; Sahasrabuddhe, A.A.; Rolland, D.C.M.; Velusamy, T.; Chung, F.; Schaller, M.; Bailey, N.G.; Betz, B.L.; Miranda, R.N.; Porcu, P.; et al. Genomic analyses reveal recurrent mutations in epigenetic modifiers and the JAK-STAT pathway in Sézary syndrome. Nat. Commun. 2015, 6, 1-10. [CrossRef] [PubMed]

24. Bastidas Torres, A.N.; Cats, D.; Mei, H.; Szuhai, K.; Willemze, R.; Vermeer, M.H.; Tensen, C.P. Genomic analysis reveals recurrent deletion of JAK-STAT signaling inhibitors HNRNPK and SOCS1 in mycosis fungoides. Genes Chromosomes Cancer 2018, 57, 653-664. [CrossRef] [PubMed]

25. McGirt, L.Y.; Jia, P.; Baerenwald, D.A.; Duszynski, R.J.; Dahlman, K.B.; Zic, J.A.; Zwerner, J.P.; Hucks, D.; Dave, U.; Zhao, Z.; et al. Whole-genome sequencing reveals oncogenic mutations in mycosis fungoides. Blood 2015, 126, 508-519. [CrossRef] [PubMed]

26. Willerslev-Olsen, A.; Krejsgaard, T.; Lindahl, L.M.; Litvinov, I.V.; Fredholm, S.; Petersen, D.L.; Nastasi, C.; Gniadecki, R.; Mongan, N.P.; Sasseville, D.; et al. Staphylococcal enterotoxin A (SEA) stimulates STAT3 activation and IL-17 expression in cutaneous T-cell lymphoma. Blood 2016, 127, 1287-1296. [CrossRef] [PubMed]

27. Willerslev-Olsen, A.; Buus, T.B.; Nastasi, C.; Blümel, E.; Gluud, M.; Bonefeld, C.M.; Geisler, C.; Lindahl, L.M.; Vermeer, M.; Wasik, M.A.; et al. Staphylococcus aureus enterotoxins induce FOXP3 in neoplastic T cells in Sézary syndrome. Blood Cancer J. 2020, 10, 1-11. [CrossRef] 
28. Lindahl, L.M.; Willerslev-Olsen, A.; Gjerdrum, L.M.R.; Nielsen, P.R.; Blümel, E.; Rittig, A.H.; Celis, P.; Herpers, B.; Becker, J.C.; Stausbøl-Grøn, B.; et al. Antibiotics inhibit tumor and disease activity in cutaneous T-cell lymphoma. Blood 2019, 134, 1072-1083. [CrossRef]

29. Yamaoka, K.; Saharinen, P.; Pesu, M.; Holt, V.E.T.; Silvennoinen, O.; O'Shea, J.J. The Janus kinases (Jaks). Genome Biol. 2004, 5, 1-6. [CrossRef]

30. Dawson, M.A.; Bannister, A.J.; Göttgens, B.; Foster, S.D.; Bartke, T.; Green, A.R.; Kouzarides, T. JAK2 phosphorylates histone H3Y41 and excludes HP1 $\alpha$ from chromatin. Nature 2009, 461, 819-822. [CrossRef]

31. Rui, L.; Drennan, A.C.; Ceribelli, M.; Zhu, F.; Wright, G.W.; Huang, D.W.; Xiao, W.; Li, Y.; Grindle, K.M.; Lu, L.; et al. Epigenetic gene regulation by Janus kinase 1 in diffuse large B-cell lymphoma. Proc. Natl. Acad. Sci. USA 2016, 113, E7260-E7267. [CrossRef]

32. Landires, I.; Núñez-Samudio, V.; Thèze, J. Short communication: Nuclear JAK3 and its involvement in CD4 activation in HIV-infected patients. AIDS Res. Hum. Retrovir. 2013, 29, 784-787. [CrossRef] [PubMed]

33. Flanagan, M.E.; Blumenkopf, T.A.; Brissette, W.H.; Brown, M.F.; Casavant, J.M.; Shang-Poa, C.; Doty, J.L.; Elliott, E.A.; Fisher, M.B.; Hines, M.; et al. Discovery of CP-690,550: A potent and selective Janus kinase (JAK) inhibitor for the treatment of autoimmune diseases and organ transplant rejection. J. Med. Chem. 2010, 53, 8468-8484. [CrossRef] [PubMed]

34. Krejsgaard, T.; Vetter-Kauczok, C.S.; Woetmann, A.; Lovato, P.; Labuda, T.; Eriksen, K.W.; Zhang, Q.; Becker, J.C.; Ødum, N. Jak3- and JNK-dependent vascular endothelial growth factor expression in cutaneous T-cell lymphoma. Leukemia 2006, 20, 1759-1766. [CrossRef] [PubMed]

35. Woetmann, A.; Nielsen, M.; Christensen, S.T.; Brockdorff, J.; Kaltoft, K.; Engel, A.-M.; Skov, S.; Brender, C.; Geisler, C.; Svejgaard, A.; et al. Inhibition of protein phosphatase $2 \mathrm{~A}$ induces serine/threonine phosphorylation, subcellular redistribution, and functional inhibition of STAT3. Proc. Natl. Acad. Sci. USA 1999, 96, 10620-10625. [CrossRef] [PubMed]

36. Zhu, F.; Hwang, B.; Miyamoto, S.; Rui, L. Nuclear import of JAK1 is mediated by a classical NLS and is required for survival of diffuse large B-cell lymphoma. Mol. Cancer Res. 2017, 15, 348-357. [CrossRef]

37. Kosugi, S.; Hasebe, M.; Tomita, M.; Yanagawa, H. Systematic identification of cell cycle-dependent yeast nucleocytoplasmic shuttling proteins by prediction of composite motifs. Proc. Natl. Acad. Sci. USA 2009, 106, 10171-10176. [CrossRef]

38. Consortium, U. UniProt: A worldwide hub of protein knowledge. Nucleic Acids Res. 2019, 47, D506-D515. [CrossRef]

39. Henderson, B.R.; Eleftheriou, A. A comparison of the activity, sequence specificity, and CRM1-dependence of different nuclear export signals. Exp. Cell Res. 2000, 256, 213-224. [CrossRef]

40. Xu, D.; Farmer, A.; Collett, G.; Grishin, N.V.; Chook, Y.M. Sequence and structural analyses of nuclear export signals in the NESdb database. Mol. Biol. Cell 2012, 23, 3677-3693. [CrossRef]

41. la Cour, T.; Kiemer, L.; Mølgaard, A.; Gupta, R.; Skriver, K.; Brunak, S. Analysis and prediction of leucine-rich nuclear export signals. Protein Eng. Des. Sel. 2004, 17, 527-536. [CrossRef]

42. Rottenberg, M.; Carow, B. SOCS3, a Major Regulator of Infection and Inflammation. Front. Immunol. 2014, 5, 58. [CrossRef]

43. Hutten, S.; Kehlenbach, R.H. CRM1-mediated nuclear export: To the pore and beyond. Trends Cell Biol. 2007, 17, 193-201. [CrossRef]

44. Kudo, N.; Matsumori, N.; Taoka, H.; Fujiwara, D.; Schreiner, E.P.; Wolff, B.; Yoshida, M.; Horinouchi, S. Leptomycin B inactivates CRM1/exportin 1 by covalent modification at a cysteine residue in the central conserved region. Proc. Natl. Acad. Sci. USA 1999, 96, 9112-9117. [CrossRef]

45. Yan, J.; Li, B.; Lin, B.; Lee, P.T.; Chung, T.H.; Tan, J.; Bi, C.; Lee, X.T.; Selvarajan, V.; Ng, S.B.; et al. EZH2 phosphorylation by JAK3 mediates a switch to noncanonical function in natural killer/T-cell lymphoma. Blood 2016, 128, 948-958. [CrossRef]

46. Senkevitch, E.; Durum, S. The promise of Janus kinase inhibitors in the treatment of hematological malignancies. Cytokine 2017, 98, 33-41. [CrossRef]

47. O'Sullivan, J.M.; Harrison, C.N. JAK-STAT signaling in the therapeutic landscape of myeloproliferative neoplasms. Mol. Cell Endocrinol. 2017, 451, 71-79. [CrossRef]

48. Lokau, J.; Garbers, C. Activating mutations of the gp130/JAK/STAT pathway in human diseases. Adv. Protein Chem. Struct. Biol. 2019, 116, 283-309. [CrossRef]

49. Gadina, M.; Johnson, C.; Schwartz, D.; Bonelli, M.; Hasni, S.; Kanno, Y.; Changelian, P.; Laurence, A.; O'Shea, J.J. Translational and clinical advances in JAK-STAT biology: The present and future of jakinibs. J. Leukoc. Biol. 2018, 104, 499-514. [CrossRef]

50. Trivedi, S.; Starz-Gaiano, M. Drosophila Jak/STAT Signaling: Regulation and Relevance in Human Cancer and Metastasis. Int. J. Mol. Sci. 2018, 19, 4056. [CrossRef]

51. Degryse, S.; de Bock, C.E.; Cox, L.; Demeyer, S.; Gielen, O.; Mentens, N.; Jacobs, K.; Geerdens, E.; Gianfelici, V.; Hulselmans, G.; et al. JAK3 mutants transform hematopoietic cells through JAK1 activation, causing T-cell acute lymphoblastic leukemia in a mouse model. Blood 2014, 124, 3092-3100. [CrossRef]

52. Gruber, C.N.; Calis, J.J.A.; Buta, S.; Evrony, G.; Martin, J.C.; Uhl, S.A.; Caron, R.; Jarchin, L.; Dunkin, D.; Phelps, R.; et al Complex Autoinflammatory Syndrome Unveils Fundamental Principles of JAK1 Kinase Transcriptional and Biochemical Function. Immunity 2020, 53, 672-684. [CrossRef]

53. Campos, L.W.; Pissinato, L.G.; Yunes, J.A. Deleterious and Oncogenic Mutations in the IL7RA. Cancers 2019, 11, 1952. [CrossRef]

54. Pérez, C.; González-Rincón, J.; Onaindia, A.; Almaráz, C.; García-Díaz, N.; Pisonero, H.; Curiel-Olmo, S.; Gómez, S.; Cereceda, L.; Madureira, R.; et al. Mutated JAK kinases and deregulated STAT activity are potential therapeutic targets in cutaneous T-cell lymphoma. Haematologica 2015, 100, e450. [CrossRef] 
55. Arora, L.; Kumar, A.P.; Arfuso, F.; Chng, W.J.; Sethi, G. The Role of Signal Transducer and Activator of Transcription 3 (STAT3) and Its Targeted Inhibition in Hematological Malignancies. Cancers 2018, 10, 327. [CrossRef]

56. Ahmed, C.M.; Noon-Song, E.N.; Kemppainen, K.; Pascalli, M.P.; Johnson, H.M. Type I IFN receptor controls activated TYK2 in the nucleus: Implications for EAE therapy. J. Neuroimmunol. 2013, 254, 101-109. [CrossRef]

57. Mishra, J.; Waters, C.M.; Kumar, N. Molecular mechanism of interleukin-2-induced mucosal homeostasis. Am. J. Physiol. Cell Physiol. 2012, 302, C735-C747. [CrossRef]

58. Lee, H.; Herrmann, A.; Deng, J.H.; Kujawski, M.; Niu, G.; Li, Z.; Forman, S.; Jove, R.; Pardoll, D.M.; Yu, H. Persistently activated Stat3 maintains constitutive NF-kappaB activity in tumors. Cancer Cell 2009, 15, 283-293. [CrossRef]

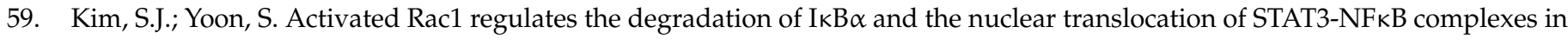
starved cancer cells. Exp. Mol. Med. 2016, 48, e231. [CrossRef]

60. Bhattacharya, S.; Schindler, C. Regulation of Stat3 nuclear export. J. Clin. Investig. 2003, 111, 553-559. [CrossRef]

61. Strebovsky, J.; Walker, P.; Lang, R.; Dalpke, A.H. Suppressor of cytokine signaling 1 (SOCS1) limits NFkappaB signaling by decreasing p65 stability within the cell nucleus. FASEB J. 2011, 25, 863-874. [CrossRef]

62. Brender, C.; Lovato, P.; Sommer, V.H.; Woetmann, A.; Mathiesen, A.M.; Geisler, C.; Wasik, M.; Ødum, N. Constitutive SOCS-3 expression protects T-cell lymphoma against growth inhibition by IFN $\alpha$. Leukemia 2005, 19, 209-213. [CrossRef]

63. Abeykoon, J.P.; Paludo, J.; Nowakowski, K.E.; Stenson, M.J.; King, R.L.; Wellik, L.E.; Wu, X.; Witzig, T.E. The effect of CRM1 inhibition on human non-Hodgkin lymphoma cells. Blood Cancer J. 2019, 9, 1-4. [CrossRef]

64. Kuruvilla, J.; Savona, M.; Baz, R.; Mau-Sorensen, P.M.; Gabrail, N.; Garzon, R.; Stone, R.; Wang, M.; Savoie, L.; Martin, P.; et al. Selective inhibition of nuclear export with selinexor in patients with non-Hodgkin lymphoma. Blood 2017, 129, $3175-3183$. [CrossRef]

65. Azizian, N.G.; Li, Y. XPO1-dependent nuclear export as a target for cancer therapy. J. Hematol. Oncol. 2020, 13, 1-9. [CrossRef]

66. Borden, K.L.B. The Nuclear Pore Complex and mRNA Export in Cancer. Cancers 2020, 13, 42. [CrossRef]

67. Verbeke, D.; Demeyer, S.; Prieto, C.; de Bock, C.E.; De Bie, J.; Gielen, O.; Jacobs, K.; Mentens, N.; Verhoeven, B.M.; Uyttebroeck, A.; et al. The XPO1 Inhibitor KPT-8602 Synergizes with Dexamethasone in Acute Lymphoblastic Leukemia. Clin. Cancer Res. 2020, 26, 5747-5758. [CrossRef]

68. Vercruysse, T.; De Bie, J.; Neggers, J.E.; Jacquemyn, M.; Vanstreels, E.; Schmid-Burgk, J.L.; Hornung, V.; Baloglu, E.; Landesman, Y.; Senapedis, W.; et al. The Second-Generation Exportin-1 Inhibitor KPT-8602 Demonstrates Potent Activity against Acute Lymphoblastic Leukemia. Clin. Cancer Res. 2017, 23, 2528-2541. [CrossRef]

69. Woetmann, A.; Lovato, P.; Eriksen, K.W.; Krejsgaard, T.; Labuda, T.; Zhang, Q.; Mathiesen, A.M.; Geisler, C.; Svejgaard, A.; Wasik, M.A.; et al. Nonmalignant T cells stimulate growth of T-cell lymphoma cells in the presence of bacterial toxins. Blood 2007, 109, 3325-3332. [CrossRef]

70. Kaltoft, K.; Bisballe, S.; Dyrberg, T.; Boel, E.; Rasmussen, P.B.; Thestrup-Pedersen, K. Establishment of two continuous T-cell strains from a single plaque of a patient with mycosis fungoides. In Vitro Cell. Dev. Biol. J. Tissue Cult. Assoc. 1992, 28, 161-167. [CrossRef]

71. Kaltoft, K.; Bisballe, S.; Rasmussen, H.F.; Thestrup-Pedersen, K.; Thomsen, K.; Sterry, W. A continuous T-cell line from a patient with Sézary syndrome. Arch. Dermatol. Res. 1987, 279, 293-298. [CrossRef] [PubMed]

72. Starkebaum, G.; Loughran, T.P.; Waters, C.A.; Ruscetti, F.W. Establishment of an IL-2 independent, human T-cell line possessing only the p70 IL-2 receptor. Int. J. Cancer 1991, 49, 246-253. [CrossRef] [PubMed] 